\title{
Home sphygmomanometers can help in the control of blood pressure: a nationwide field survey
}

\author{
Tekin Akpolat ${ }^{1} \cdot$ Mustafa Arici $^{2} \cdot$ Sule Sengul $^{3} \cdot$ Ulver Derici $^{4} \cdot$ Sukru Ulusoy $^{5} \cdot$ Sehsuvar Erturk $^{3} \cdot$ Yunus Erdem $^{2}$
}

Received: 25 July 2017 / Revised: 16 October 2017 / Accepted: 25 November 2017 / Published online: 19 March 2018

(c) The Author(s) 2018. This article is published with open access

\begin{abstract}
Home blood pressure monitoring (HBPM), which integrates patients into their treatment program, is a self-management tool. The prevalence of home sphygmomanometer ownership and patient compliance with HBPM guidelines are not well known, especially in developing and underdeveloped countries. The aims of this study were to measure the prevalence of home sphygmomanometer ownership among hypertensive subjects through a nationwide field survey (PatenT2), to investigate the validation of sphygmomanometers and consistency of the user arm circumference and cuff size of the upper-arm device owned, as well as to compare blood pressure (BP) readings between hypertensive subjects who have or do not have a sphygmomanometer. Sample selection was based on a multistratified proportional sampling procedure to select a nationally representative sample of the adult population $(n=5437)$. Of 1650 hypertensive subjects, $332(20.1 \%)$ owned a device, but the percentage of patients who owned a sphygmomanometer was $28.8 \%$ among patients who were aware of their hypertension (260/902). The usage of wrist devices and nonvalidated devices is common, and selection of an appropriate cuff size is ignored. Linear-regression analysis showed that owning a BP monitor is associated with decreases of $3.7 \mathrm{mmHg}$ and $2.8 \mathrm{mmHg}$ for systolic and diastolic BPs, respectively. Many patients do not own a sphygmomanometer. The decrease of systolic and diastolic BPs among BP monitor owners is a striking finding. The implementation of a hypertension care program consisting of sphygmomanometer reimbursement and training of patients in its use for HBPM might be costeffective.
\end{abstract}

\section{Introduction}

Home blood pressure monitoring (HBPM) integrates patients into their treatment program and is a common selfmanagement tool, especially in developed countries [1-5]. Substantial evidence regarding the usefulness of HBPM in the management of hypertension (HT) has accumulated over the last two decades [6-9], and HBPM is recommended in HT guidelines [10-14]. Home blood pressure

\footnotetext{
Tekin Akpolat

tekinakpolat@yahoo.com

Istinye University Liv Hospital, Istanbul, Turkey

2 Hacettepe University Faculty of Medicine, Ankara, Turkey

3 Ankara University Faculty of Medicine, Ankara, Turkey

4 Gazi University Faculty of Medicine, Ankara, Turkey

5 Karadeniz Technical University Faculty of Medicine, Trabzon, Turkey
}

(BP) monitoring can also be supported by pharmacy assistance, telemonitoring or self-management programs [1517]. A recent systematic review found HBPM to be superior to office measurements in diagnosing uncontrolled HT, assessing the efficiency of antihypertensive agents, and improving patients' compliance and HT control [18].

An accurate and validated [19-22] sphygmomanometer, the correct measurement of $\mathrm{BP}$ and adherence to the current guidelines regarding when and how BP should be measured at home settings are the essentials of reliable HBPM. However, the prevalence of home sphygmomanometer ownership and patient awareness and compliance with the HBPM guidelines are not well known, especially in developing and underdeveloped countries. In Turkey, a developing country with a high prevalence of HT (30.3\%), we conducted a survey (published in this journal) using computer-assisted telephone interviewing among 2747 hypertensive patients in 2011; of the respondents, 1281 (46.6\%) had a home sphygmomanometer [23-26]. Computer-assisted telephone interviewing has some limitations; therefore, we were unable to investigate the 
validation of the sphygmomanometers, the consistency of the arm circumference of the user and the cuff size of the upper-arm device owned and the possible beneficial effects of having a sphygmomanometer. The aims of this study were to measure the prevalence of home sphygmomanometer ownership among hypertensive subjects through a nationwide field survey [27], to investigate the validation of sphygmomanometers, to determine the consistency of user arm circumference and the cuff size of the upper-arm device owned and to compare BP readings between hypertensive subjects who have or do not have a sphygmomanometer.

\section{Methods}

\section{Research population and sampling}

The PatenT2 study [27] was designed, directed and fully supported by the Turkish Society of Hypertension and Renal Diseases. PatenT2 sample selection was based on a multistratified proportional sampling procedure to select a nationally representative sample of the adult population over 18 years of age $(n=5437)$. During the home visits, a standard face-to-face interview questionnaire was administered to collect data on social demographics and behavioral characteristics, and a minimum of three consecutive BP measurements were taken. A total of 5437 individuals [2704 men (49.7\%) and 2733 women (50.3\%), $74.3 \%$ urban and $25.7 \%$ rural residents] were randomly selected from 26 cities, and all completed the face-to-face interview questionnaire, and BP and anthropometric measurements were taken over 92 days.

\section{Data collection}

In total, 30 health professionals who attended a training course to familiarize themselves with the survey and measurement techniques before the survey participated. The health professionals were trained in BP measurement and anthropometric measurement protocols.

Each team was given the same model of an automatic oscillometric BP-measuring device (Omron M3 Intellisense, HEM-7051-E, Tokyo, Japan), two cuffs $(22-32 \mathrm{~cm}$ and $33-42 \mathrm{~cm}$ ), a weighing scale and a measuring tape. In addition, each team had an iPad 2, which was used to transfer the collected data electronically via the Internet to the main computer at the study center. In the study center, two supervisors were responsible for the quality control of the collected data.

\section{Measurements and definitions}

Systolic and diastolic blood pressure (SBP, DBP), heart rate, weight, height, and waist and arm circumferences were measured according to standard protocols. Body mass index (BMI) was also calculated. Obesity and overweight were defined as BMIs of at least 30 and $25-29.9 \mathrm{~kg} / \mathrm{m}^{2}$, respectively.

BP measurements were completed according to the recommendations at the time the study was performed [28]. None of the participants had alcohol or tea/coffee intake nor had smoked at least $30 \mathrm{~min}$ prior to the measurement. Initially, each participant's BP was measured using appropriately sized cuffs after 5 min of rest in a sitting position with his/her back supported. If the reading was higher in one arm, that arm was used for the following measurements. At least three consecutive BP measurements were obtained, with a time interval of at least 2 min between each measurement according to the recommendations of the European Society of Hypertension (ESH). If the difference between the last two measurements was $<5 \mathrm{mmHg}$, the arithmetic mean of the second and third BP measurements was noted as the visit BP. A fourth or multiple additional measurements were obtained when there was a difference of $\geq 5 \mathrm{mmHg}$ between the last two measurements. When the difference between the last two measurements was $<5$ $\mathrm{mmHg}$, the arithmetic mean of the last two BP sure measurements was recorded as the visit BP.

Hypertension was defined as an average SBP of $\geq 140$ $\mathrm{mmHg}$ and an average DBP of $\geq 90 \mathrm{mmHg}$, or previously diagnosed HT, and/or the use of antihypertensive medication regardless of $\mathrm{BP}$ readings. Awareness of HT was described as any previous diagnosis of HT by a health professional among the participants identified as having HT. Treatment of HT was defined as the use of antihypertensive medication at the time of the interview. Control of HT was defined as an $\mathrm{SBP}<140 \mathrm{mmHg}$ and a $\mathrm{DBP}<90 \mathrm{mmHg}$ [23]. The control rates among patients receiving antihypertensive medication were also recorded.

\section{Arm circumference}

Mid-arm circumference (the midpoint of the acromion and olecranon) was measured with a plastic tape on bare extremities. Arm circumference was measured from both arms, but only the measurements taken from the right arm were reported. The right mid-arm circumference for the PatenT study, conducted in 2003 [20], was calculated from the following formula derived from the linear-regression analysis in the PatenT2 study to identify independent predictors of right mid-arm circumference:

Right-arm circumference $=21.303+((-0.001) * a g e)+$ $((-1.245) *$ gender $)+(0.379 * \mathrm{BMI})+(0.137 *$ residence $)$ 


\section{Cuff size and device validation}

Cuff size was checked only for upper-arm devices including aneroid and mercury devices. Information regarding the cuff size of the upper-arm devices was taken from the device or box of the device, if it was available. Unless the owner gave specific information, the device was considered standard $(22-32 \mathrm{~cm})$. An automated upper-arm device listed and recommended on either or both of the dabl Educational Trust and the British Hypertension Society websites [29, 30] was considered "validated".

\section{Telephone survey in 2017}

In 2017, 5 years after the field survey, 1318 hypertensive subjects who did not own a sphygmomanometer were called by telephone to ask whether they now owned a sphygmomanometer. If they had one, the type of the sphygmomanometer (nonautomated, automated upper arm or automated wrist) was recorded.

\section{Statistical analysis}

Predictive analytics software (PASW statistics 18, 2009) was used for the analysis. A type-I error level of less than $5 \%$ was used to infer statistical significance. The variables were investigated using visual (histograms, probability plots) and analytical (Kolmogorov-Smirnov/Shapiro-Wilk tests) methods to determine whether they were normally distributed. Univariate analyses were used to identify the variables associated with the possession of a blood-pressure measuring device of hypertensive patients who were aware of their HT; for this, the chi-square and Mantel-Haenszel tests were used as appropriate. The Mann-Whitney $U$ test was used for the comparison of SBP and diastolic BPs both in the HT groups and the aware group in terms of the device type and device validation. For the multivariate analysis, the possible factors identified with univariate analyses were further entered into a logistic regression analysis with backward selection to determine the independent predictors of possessing a blood-pressure measuring device for hypertensive patients who were aware of their HT. Hosmer-Lemeshow and Pearson's goodness-of-fit statistics were used to evaluate the model fit. To investigate the factors affecting the baseline SBP and DBPs in the aware group, multivariate linear-regression analysis was performed.

\section{Results}

The basic demographic information of the participants was published previously [23]. A total of 1650 participants
(30.3\%) of the PatenT2 study were hypertensive, and $54.7 \%$ of the hypertensive patients $(n=902)$ were aware of their diagnosis. The use of pharmacological treatment and control rates were $47.4 \%$ and $28.7 \%$, respectively. Among the 5437 participants including normotensive and unaware hypertensive patients, $660(12 \%)$ had a home sphygmomanometer (95\% CI: $11.3-13.0 \%$ ), and the percentage of patients owning a device was $8.7 \%$ (328/3787). Of 1650 hypertensive subjects, $332(20.1 \%)$ had a device $(95 \% \mathrm{CI}$ : 18.2-22.1), but the percentage of patients owning a sphygmomanometer was $28.8 \%$ among patients who were aware of their disease (260/902).

\section{Factors associated with the ownership of a sphygmomanometer among hypertensive patients who were aware of their HT}

Various factors related to the ownership of a sphygmomanometer among the patients who were aware of their HT are presented in Tables 1 and 2. Sphygmomanometer ownership was significantly higher among participants living in urban areas, participants with higher education status, participants with higher income level and patients using antihypertensive medication. Multivariate logistic regression analysis demonstrated that the factors associated with owning a sphygmomanometer were female gender, older age, higher educational status, living in urban areas and antihypertensive drug use (Table 2).

\section{Device information}

Of 660 devices, 482 (73\%) were automated, wrist devices being more common. Table 3 shows the types of sphygmomanometers owned among all participants and hypertensive subjects who were aware of their HT.

\section{HBPM practice among participants}

Of the device owners, 429 (65\%) stated that they had not had any training regarding the operation of the device. The participants learned the usage of their devices mainly from their relatives and the sellers; the percentage of patients who learned to use the device from healthcare professionals, physicians or nurses was $29 \%$, including relatives working in health care.

Among patients who were aware of their HT, 50\% stated that they had not had any training regarding the operation of the device, and the percentage of patients who learned to use the device from healthcare professionals was $32 \%$. Among the patients who were aware of their HT, 204 had automated devices, $74(36 \%)$ of which were validated. Twenty-two (18\%) of the 120 wrist devices and $52(62 \%)$ of the 84 automated upper-arm devices were validated. 
Table 1 Factors associated with possession of a blood-pressure measuring device in the hypertensive population who were aware of their hypertension

\begin{tabular}{|c|c|c|c|}
\hline Variable & $\begin{array}{l}\text { Patients possessing a } \\
\text { blood-pressure measuring } \\
\text { device } \\
(\%)\end{array}$ & Statistical test used for analysis & $p$ \\
\hline Gender & & Pearson chi-square & \\
\hline Female & $175(29.7)$ & & 0.446 \\
\hline Male & $85(27.2)$ & & \\
\hline Age groups & & $\begin{array}{l}\text { Mantel-Haenszel test (linear- } \\
\text { by-linear association) }\end{array}$ & \\
\hline $18-29$ years & $0(0.0)$ & & 0.267 \\
\hline 30-39 years & $6(17.1)$ & & \\
\hline $40-49$ years & $35(26.5)$ & & \\
\hline $50-59$ years & $82(32.0)$ & & \\
\hline $60-69$ years & $78(29.0)$ & & \\
\hline$\geq 70$ years & $59(28.9)$ & & \\
\hline Residence & & Pearson chi-square & \\
\hline Urban & $227(33.1)$ & & $<0.001$ \\
\hline Rural & $33(15.2)$ & & \\
\hline Educational status & & $\begin{array}{l}\text { Mantel-Haenszel test (linear- } \\
\text { by-linear association) }\end{array}$ & \\
\hline Illiterate & $20(20.6)$ & & $<0.001$ \\
\hline Literate & $27(21.8)$ & & \\
\hline Primary school graduate & $127(27.9)$ & & \\
\hline Middle school graduate & $24(32.9)$ & & \\
\hline High school graduate & $33(36.3)$ & & \\
\hline University graduate & $29(47.5)$ & & \\
\hline Monthly income level & & $\begin{array}{l}\text { Mantel-Haenszel test (linear- } \\
\text { by-linear association) }\end{array}$ & \\
\hline$<1001 \mathrm{TL}^{\mathrm{a}}$ & $142(24.8)$ & & $<0.001$ \\
\hline$\geq 1000 \mathrm{TL}$ & $102(37.0)$ & & \\
\hline Blood-pressure categories & & $\begin{array}{l}\text { Mantel-Haenszel test (linear- } \\
\text { by-linear association) }\end{array}$ & \\
\hline Optimal & $60(37.3)$ & & 0.001 \\
\hline Normal & $52(34.4)$ & & \\
\hline High normal & $36(22.2)$ & & \\
\hline Stage 1 hypertension & $78(28.4)$ & & \\
\hline Stage 2 hypertension & $27(24.8)$ & & \\
\hline Stage 3 hypertension & $7(15.9)$ & & \\
\hline Body mass index & & $\begin{array}{l}\text { Mantel-Haenszel test (linear- } \\
\text { by-linear association) }\end{array}$ & \\
\hline $\begin{array}{l}\text { Underweight }\left(<18.5 \mathrm{~kg} / \mathrm{m}^{2}\right) \\
+ \text { normal weight }\left(18.5-24.9 \mathrm{~kg} / \mathrm{m}^{2}\right)\end{array}$ & $22(22.2)$ & & 0.045 \\
\hline Overweight $\left(25-29.9 \mathrm{~kg} / \mathrm{m}^{2}\right)$ & 75 (26.9) & & \\
\hline Obese $\left(\geq 30 \mathrm{~kg} / \mathrm{m}^{2}\right)$ & $163(31.2)$ & & \\
\hline Antihypertensive drug usage & & Pearson chi-square & \\
\hline Yes & $239(30.7)$ & & 0.002 \\
\hline No & $21(17.1)$ & & \\
\hline
\end{tabular}

a 1 Euro=2.4 TL March 2012 
Table 2 Results of multivariate logistic regression analyses for ownership of a blood-pressure measuring device

\begin{tabular}{llll}
\hline Variables $^{\mathrm{a}}$ & Multivariate $(p)$ & Odds ratio & $95 \% \mathrm{CI}$ \\
\hline $\begin{array}{l}\text { Gender (female) } \\
\text { Age }\end{array}$ & 0.054 & 1.390 & $0.995-1.943$ \\
$\quad 18-39$ years & & 1.0 (reference) & 1.0 (reference) \\
$40-49$ years & 0.138 & 2.088 & $0.788-5.528$ \\
$50-59$ years & 0.025 & 2.903 & $1.144-7.369$ \\
$\begin{array}{l}\text { 60-69 years } \\
70 \text { years and }\end{array}$ & 0.031 & 2.805 & $1.100-7.149$ \\
$\begin{array}{l}\text { above } \\
\text { Living in urban }\end{array}$ & 0.021 & 3.109 & $1.190-8.124$ \\
$\begin{array}{l}\text { areas } \\
\text { Educational } \\
\text { status }\end{array}$ & $<0.001$ & 2.609 & $1.729-3.936$ \\
$\begin{array}{l}\text { Illiterate } \\
\text { Literate }\end{array}$ & 0.841 & 1.0 (reference) & 1.0 (reference) \\
$\begin{array}{l}\text { Primary school } \\
\text { graduate }\end{array}$ & 0.060 & 1.071 & $0.548-2.091$ \\
$\begin{array}{l}\text { Middle school } \\
\text { graduate }\end{array}$ & 0.049 & 1.740 & $0.976-3.101$ \\
$\begin{array}{l}\text { High school } \\
\text { graduate }\end{array}$ & 0.006 & 2.153 & $1.003-4.620$ \\
$\begin{array}{l}\text { University } \\
\text { graduate }\end{array}$ & $<0.001$ & 2.733 & $1.332-5.607$ \\
$\begin{array}{l}\text { Antihypertensive } \\
\text { drug usage }\end{array}$ & 0.012 & 3.991 & $1.862-8.555$ \\
\hline
\end{tabular}

CI confidence interval.

${ }^{a}$ The variables included in the multivariate logistic regression analysis were gender, age, educational status, living in urban areas, income level, blood-pressure categories, awareness of hypertension, antihypertensive drug usage, and body mass index. Only variables having significant differences are shown.

Table 3 Types of sphygmomanometers among all participants (including aware hypertensive subjects) and hypertensive subjects who were aware of their hypertension in 2012

\begin{tabular}{lll}
\hline Type of device & All participants & $\begin{array}{l}\text { Aware hypertensive } \\
\text { subjects } \\
(n)\end{array}$ \\
\hline Automated wrist & 294 & 120 \\
Automated upper arm & 188 & 84 \\
Aneroid & 132 & 50 \\
Mercury & 4 & 1 \\
Not at home & 42 & 5 \\
Total & 660 & 260 \\
\hline
\end{tabular}

\section{Arm circumference and cuff size}

The mean right-arm circumference was $30.0 \mathrm{~cm}$ among all participants and was $29.6 \mathrm{~cm}$ for the participants of the PATENT study. The mean right-arm circumference was wider in hypertensive patients than that in hypertensive patients in the PATENT study $(31 \mathrm{~cm}$ vs. $30.6 \mathrm{~cm})$. The frequency of requiring a large cuff was $32 \%$ among aware hypertensive patients having an upper-arm device, but only one had a cuff $\geq 33 \mathrm{~cm}$.

\section{The association between possessing a home sphygmomanometer and BP levels in hypertensive patients who were aware of their disease}

The mean SBP and DBPs among aware patients who had a BP monitor were $5.8 \mathrm{mmHg}$ and $3.4 \mathrm{mmHg}$ lower than those of patients not having a device. Validated and/or upper-arm devices were associated with lower SBP and DBPs (Table 4).

\section{The results of linear-regression analysis}

While the baseline SBP was $143.9 \mathrm{mmHg}$ in the HT awareness group, linear-regression analysis indicated that being male resulted in a $3.125-\mathrm{mmHg}$ increase, and every 1year increase in age resulted in a $0.291-\mathrm{mmHg}$ increase (an $\sim 3$ - $\mathrm{mmHg}$ increase with every 10 -year increase in age); furthermore, living in rural areas resulted in a $2.369-\mathrm{mmHg}$ increase in the baseline SBP $(p=0.003, p<0.001$ and $p=$ 0.027 , respectively). On the other hand, each categorical increase in income level resulted in a $2.401-\mathrm{mmHg}$ decrease, antihypertensive drug use resulted in a 14.386$\mathrm{mmHg}$ decrease and the presence of a device at home resulted in a 3.744-mmHg decrease in the baseline SBP

Table 4 Mean systolic blood pressure (SBP) and diastolic blood pressure (DBP) according to the device type and validation status (only automatic devices are shown)

\begin{tabular}{lll}
\hline & $\begin{array}{l}\text { SBP } \\
\mathrm{mmHg}\end{array}$ & $\begin{array}{l}\mathrm{DBP} \\
\mathrm{mmHg}\end{array}$ \\
\hline Device type & & \\
Upper arm & 133 & 73 \\
Wrist & 141 & 76 \\
& $P=0.010$ & $P=0.069$ \\
Validation status & & \\
Validated (upper arm+wrist) & 133 & 72 \\
Nonvalidated (upper arm+wrist) & 140 & 77 \\
& $P=0.011$ & $P=0.014$ \\
Validated (upper arm) & 132 & 72 \\
Nonvalidated (upper arm) & 135 & 76 \\
& $P=0.293$ & $P=0.093$ \\
Validated (wrist) & 135 & 75 \\
Nonvalidated (wrist) & 142 & 77 \\
& $P=0.161$ & $P=0.484$ \\
\hline
\end{tabular}


Table 5 Linear-regression analysis of factors affecting systolic blood pressure

\begin{tabular}{lll}
\hline Variables & Multivariate $(p)$ & $\beta$ \\
\hline Constant coefficient & $<0.001$ & 143.923 \\
Gender (male) & 0.003 & 3.125 \\
Age & $<0.001$ & 0.291 \\
Living in rural areas & 0.027 & 2.369 \\
Educational status & 0.214 & -0.578 \\
Income level & 0.002 & -2.401 \\
Euro-stat region & 0.550 & 0.085 \\
BMI & 0.342 & -0.087 \\
Antihypertensive drug usage & $<0.001$ & -14.386 \\
Ownership of a blood-pressure & 0.002 & -3.744 \\
measuring device & & \\
\hline
\end{tabular}

$(p=0.002, \quad p<0.001 \quad$ and $\quad p=0.002, \quad$ respectively) (Table 5).

While the baseline DBP was $91.5 \mathrm{mmHg}$ in the HT awareness group, linear-regression analysis indicated that being male resulted in a 1.384-mmHg increase and living in rural areas resulted in a $2.335-\mathrm{mmHg}$ increase in the baseline DBP $(p=0.031$ and $p<0.001$, respectively). On the other hand, every 1 -year increase in age resulted in a 0.145 $\mathrm{mmHg}$ decrease $(\sim 1.5$-mmHg decrease with every 10 -year increase in age), antihypertensive drug use resulted in a 6.206- $\mathrm{mmHg}$ decrease and the presence of a device at home resulted in a 2.837-mmHg decrease in the baseline DBP ( $p$ $<0.001$ for each) (Table 6).

Linear-regression analysis of factors affecting SBP and DBP after stratification by antihypertensive drug use is shown in Table 7 (the method and variables are the same as those in Tables 5 and 6; only the ownership of a bloodpressure measuring device variable is shown). The association between possessing a BP device and BP decrease remained after stratification by antihypertensive drug use.

Table 6 Linear-regression analysis of factors affecting diastolic blood pressure.

\begin{tabular}{lll}
\hline Variables & Multivariate $(p)$ & $\beta$ \\
\hline Constant coefficient & $<0.001$ & 91.537 \\
Gender (male) & 0.031 & 1.384 \\
Age & $<0.001$ & -0.145 \\
Living in rural areas & $<0.001$ & 2.335 \\
Educational status & 0.674 & -0.121 \\
Income level & 0.083 & -0.849 \\
Euro-stat region & 0.474 & 0.063 \\
BMI & 0.497 & 0.038 \\
Antihypertensive drug usage & $<0.001$ & -6.206 \\
Ownership of a blood-pressure measuring & $<0.001$ & -2.837 \\
device & & \\
\hline
\end{tabular}

Table 7 Linear-regression analysis of factors affecting systolic blood pressure (SBP) and diastolic blood pressure (DBP) after stratification by the antihypertensive drug use (method and variables same as Tables 5 and 6, only ownership of a blood-pressure measuring device variable is shown)

\begin{tabular}{lll}
\hline & Multivariate $(p)$ & $\beta$ \\
\hline Antihypertensive drug (+) & & \\
SBP & 0.019 & -4.107 \\
DBP & 0.004 & -2.880 \\
Antihypertensive drug (-) & & \\
SBP & 0.160 & -2.566 \\
DBP & 0.030 & -2.758 \\
\hline
\end{tabular}

\section{Telephone survey in 2017}

In total, 1318 hypertensive PatenT2 participants did not have a BP monitor in 2012, and 437 were reached by telephone in 2017. After 2012, $254(58.1 \%)$ of 437 patients bought a new device. The types of devices were automated upper arm $(n=122,48 \%)$, automated wrist $(n=82,33 \%)$ and nonautomated $(n=48,19 \%)$. The device type of two owners could not be determined. Figure 1 shows the change in sphygmomanometer type with time.

\section{Discussion}

The present study confirmed the findings of the previous study. Only the new findings will be discussed. Among 902 hypertensive patients who were aware of their disease, 260 (28.8\%) had a home sphygmomanometer, a lower rate than that found in our first survey in 2011 (28.8 vs. $46.6 \%)$. As mentioned in our paper [23], the first survey using computer-assisted telephone interviewing had some limitations. The findings of the 2017 telephone survey supported a possible Hawthorne effect and showed that the frequency of ownership of a sphygmomanometer had increased. Forty two $(6 \%)$ of the 660 devices were not in the houses of the participants during our visit in this study, which indicated

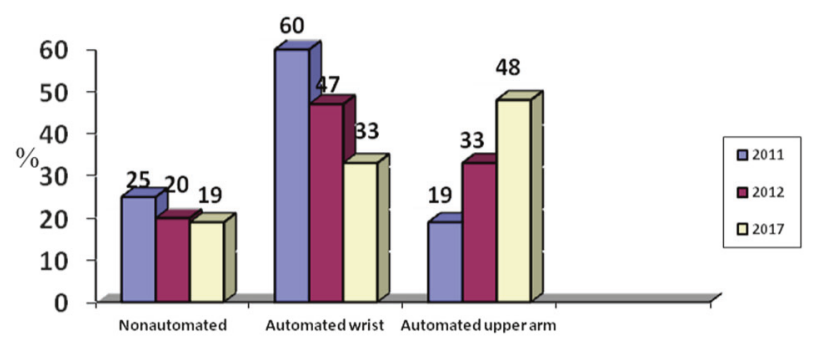

Fig. 1 Comparison of sphygmomanometer types in three surveys by time (the results are expressed as percentages) 
that BP monitors can be shared among neighbors and relatives.

The most striking finding of our study was the demonstration of an association between sphygmomanometer ownership and BP decrease [31, 32] in a nationwide field survey. The SBP and DBPs among aware hypertensive patients possessing a home BP monitor were 5.8 and 3.4 $\mathrm{mmHg}$ lower, respectively, than those of patients that did not have one. The linear-regression analysis showed that possessing a BP device is associated with a decrease of 3.7 $\mathrm{mmHg}$ and $2.8 \mathrm{mmHg}$ on SBP and DBPs, respectively. To our knowledge, similar nationwide data are not available. The findings of this study support previous data regarding the usefulness of HBPM [33, 34]. Moreover, it should be kept in mind that nonadherence to the recommended guidelines for BP measurement is a common problem [35], and the consecutive measurement of BP (two times) may be more useful [36].

The cause of lower BP in patients possessing a sphygmomanometer is not known, and the current study was not designed to find the answer to this question. It can be argued that compliant patients willing to learn, measure and control their BP bought a sphygmomanometer, as reported by Ayala et al. [37]; regardless, the association between possessing a BP monitor and lower BP supports the notion that HBPM is a supplementary tool in the control of BP. Ostchega et al. [38] reported that hypertensive patients who received providers' recommendations to perform HBPM were more likely to do so than those who did not receive recommendations. Home $\mathrm{BP}$ monitoring and home BP monitor reimbursement have been recommended by many guidelines [10-14]. Our data support the previous evidence suggesting that HBPM may be cost-effective [2, 18, 34]; therefore, home BP monitor reimbursement should be encouraged. Lifestyle changes are the effective measures in the management of HT. Home BP monitoring is a lifestyle change that can increase treatment adherence [14]. Dietary salt reduction is an effective lifestyle change in the management of HT and can save billions of healthcare-related payments [39]. Similarly, owning a home BP monitor may play a role in improving BP control and could save HTrelated treatment expenses, including the cost of medication. In addition, HBPM is a good supplementary tool for the improvement of BP control in low-income countries [40].

There were problems in the patients' choice of a BP monitor, such as device validation and the use of an appropriate cuff bladder for nonstandard arm circumference sizes in addition to the dominance of wrist devices. It is encouraging to see the increasing number of upper arm automated sphygmomanometers (Fig. 1). Since obesity and arm circumference are increasing, problems related to cuff size may also increase. Many nonvalidated devices are being introduced into the market [41-43], and only $36 \%$ of the devices in this study were validated. Blood pressure was lower among hypertensive patients possessing a validated and/or upper-arm BP monitor (Table 4). Since the use of an appropriate cuff size is essential for the accurate measurement of BP [3, 10, 11], overweight and obese patients often require sphygmomanometers with large or extra-large cuffs. Although most regular cuff sizes are appropriate for patients having an arm circumference of $22-32 \mathrm{~cm}$, more than $30 \%$ of the patients having an upper-arm device required large cuffs, but only one (less than $1 \%$ ) patient had a large cuff, indicating ignorance of the problem.

This was the first study investigating the arm circumference of a Turkish population, and the results demonstrated that arm circumference and the frequency of patients requiring a large cuff were increased compared to 2003 [24]. Since obesity continues to increase and arm circumference is closely associated with obesity [44], it is expected that the number of patients requiring a large cuff will increase.

In conclusion, despite market prices being reasonable (cheaper than 30-50 Euros; most patients can afford this in Turkey), many patients do not have a sphygmomanometer. The use of wrist devices and nonvalidated devices is common, and the selection of an appropriately sized cuff is ignored in obese patients. The demonstration of an association between sphygmomanometer ownership and BP decrease was a striking finding. As demonstrated in several studies, the implementation of a HT care program consisting of sphygmomanometer reimbursement, training patients on how to use the device and HBPM can be costeffective.

Acknowledgements The study was sponsored by the Turkish Society of Hypertension and Renal Diseases. The field study, training and supervision of the field healthcare workers and data collection were carried out by the OMEGA Contract Research Organization in Turkey. The sponsor, the Turkish Society of Hypertension and Renal Diseases, assigned the study group and was involved in the study design.

Funding The present study was supported by the Turkish Society of Hypertension and Renal Diseases (Ankara, Turkey).

\section{Compliance with ethical standards}

Conflict of interest The authors declare that they have no conflict of interest.

Open Access This article is licensed under a Creative Commons Attribution-NonCommercial-NoDerivatives 4.0 International License, which permits any non-commercial use, sharing, distribution and reproduction in any medium or format, as long as you give appropriate credit to the original author(s) and the source, and provide a link to the Creative Commons license. You do not have permission under this 
license to share adapted material derived from this article or parts of it. The images or other third party material in this article are included in the article's Creative Commons license, unless indicated otherwise in a credit line to the material. If material is not included in the article's Creative Commons license and your intended use is not permitted by statutory regulation or exceeds the permitted use, you will need to obtain permission directly from the copyright holder. To view a copy of this license, visit http://creativecommons.org/licenses/by-nc-nd/4.0/.

\section{References}

1. Pickering TG, Miller NH, Ogedegbe G, Krakoff LR, Artinian NT, Goff D, American Heart Association; American Society of Hypertension; Preventive Cardiovascular Nurses Association. Call to action on use and reimbursement for home blood pressure monitoring: a joint scientific statement from the American Heart Association, American Society of Hypertension, and Preventive Cardiovascular Nurses Association. J Cardiovasc Nurs. 2008;23:299-323.

2. Carrera PM, Lambooij MS. Implementation of out-of-office blood pressure monitoring in the Netherlands: from clinical guidelines to patients' adoption of innovation. Medicine (Baltimore). 2015;94: e1813.

3. Shimamoto K, Ando K, Fujita T, Hasebe N, Higaki J, Horiuchi M, Imai Y, Imaizumi T, Ishimitsu T, Ito M, Ito S, Itoh $\mathrm{H}$, Iwao $\mathrm{H}$, Kai H, Kario K, Kashihara N, Kawano Y, Kim-Mitsuyama S, Kimura G, Kohara K, Komuro I, Kumagai H, Matsuura H, Miura K, Morishita R, Naruse M, Node K, Ohya Y, Rakugi H, Saito I, Saitoh S, Shimada K, Shimosawa T, Suzuki H, Tamura K, Tanahashi N, Tsuchihashi T, Uchiyama M, Ueda S, Umemura S, Japanese Society of Hypertension Committee for Guidelines for the Management of Hypertension. The Japanese Society of Hypertension Guidelines for the Management of Hypertension (JSH 2014). Hypertens Res. 2014;37:253-392.

4. Krecke HJ, Lütkes P, Maiwald M. Patient assessment of selfmeasurement of blood pressure: results of a telephone survey in Germany. J Hypertens. 1996;14:323-326.

5. Cuspidi C, Meani S, Lonati L, Fusi V, Magnaghi G, Garavelli G, Palumbo G, Pini C, Vaccarella A, Parati G, Leonetti G, Zanchetti A, Lombardy Regional Section of the Italian Hypertension Society. Prevalence of home blood pressure measurement among selected hypertensive patients: results of a multicenter survey from six hospital outpatient hypertension clinics in Italy. Blood Press. 2005;14:251-256.

6. Cuspidi C, Sala C, Casati A, Bombelli M, Grassi G, Mancia G. Clinical and prognostic value of hypertensive cardiac damage in the PAMELA study. Hypertens Res. 2017;40:329-335.

7. Ntineri A, Stergiou GS, Thijs L, Asayama K, Boggia J, Boubouchairopoulou N, Hozawa A, Imai Y, Johansson JK, Jula AM, Kollias A, Luzardo L, Niiranen TJ, Nomura K, Ohkubo T, Tsuji I, Tzourio C, Wei FF, Staessen JA. Relationship between office and home blood pressure with increasing age: The International Database of HOme blood pressure in relation to Cardiovascular Outcome (IDHOCO). Hypertens Res. 2016;39:612-7.

8. Kario K, Saito I, Kushiro T, Teramukai S, Yaginuma M, Mori Y, Okuda Y, Kobayashi F, Shimada K. Persistent olmesartan-based blood pressure-lowering effects on morning hypertension in Asians: the HONEST study. Hypertens Res. 2016;39:334-41.

9. Ishikura K, Obara T, Kikuya M, Satoh M, Hosaka M, Metoki H, Nishigori $\mathrm{H}$, Mano N, Nakayama M, Imai Y, Ohkubo T, JHOME-Morning Study Group. Home blood pressure level and decline in renal function among treated hypertensive patients: the J-HOME-Morning Study. Hypertens Res. 2016;39:107-12.

10. Imai Y, Kario K, Shimada K, Kawano Y, Hasebe N, Matsuura H, Tsuchihashi T, Ohkubo T, Kuwajima I, Miyakawa M, Japanese
Society of Hypertension Committee for Guidelines for Selfmonitoring of Blood Pressure at Home. The Japanese Society of Hypertension Guidelines for Self-monitoring of Blood Pressure at Home (second edition). Hypertens Res. 2012;35:777-95.

11. Parati G, Stergiou GS, Asmar R, Bilo G, DeLeeuw P, Imai Y, Kario K, Lurbe E, Manolis A, Mengden T, O’Brien E, Ohkubo T, Padfield P, Palatini P, Pickering TG, Redon J, Revera M, Ruilope LM, Shennan A, Staessen JA, Tisler A, Waeber B, Zanchetti A, Mancia G. European Society of Hypertension practice guidelines for home blood pressure monitoring. J Hum Hypertens. 2010;24:779-785.

12. Leung AA, Nerenberg K, Daskalopoulou SS, McBrien K, Zarnke KB, Dasgupta K, Cloutier L, Gelfer M, Lamarre-Cliche M, Milot A, Bolli P, Tremblay G, McLean D, Tobe SW, Ruzicka M, Burns KD, Vallée M, Prasad GV, Lebel M, Feldman RD, Selby P, Pipe A, Schiffrin EL, McFarlane PA, Oh P, Hegele RA, Khara M, Wilson TW, Penner SB, Burgess E, Herman RJ, Bacon SL, Rabkin SW, Gilbert RE, Campbell TS, Grover S, Honos G, Lindsay P, Hill MD, Coutts SB, Gubitz G, Campbell NR, Moe GW, Howlett JG, Boulanger JM, Prebtani A, Larochelle P, Leiter LA, Jones C, Ogilvie RI, Woo V, Kaczorowski J, Trudeau L, Petrella RJ, Hiremath S, Drouin D, Lavoie KL, Hamet P, Fodor G, Grégoire JC, Lewanczuk R, Dresser GK, Sharma M, Reid D, Lear SA, Moullec G, Gupta M, Magee LA, Logan AG, Harris KC, Dionne J, Fournier A, Benoit G, Feber J, Poirier L, Padwal RS, Rabi DM; CHEP Guidelines Task Force. Hypertension Canada's 2016 Canadian Hypertension Education Program Guidelines for Blood Pressure Measurement, Diagnosis, Assessment of Risk, Prevention, and Treatment of Hypertension. Can J Cardiol. 2016;32: 569-88.

13. National Heart Foundation of Australia. Guideline for the diagnosis and management of hypertension in adults - 2016. Melbourne: National Heart Foundation of Australia; 2016.

14. Mancia G, Fagard R, Narkiewicz K, Redon J, Zanchetti A, Böhm M, ChristiaensT, Cifkova R, De Backer G, Dominiczak A, Galderisi M, Grobbee DE, Jaarsma T, Kirchhof P, Kjeldsen SE, Laurent S, Manolis AJ, Nilsson PM, Ruilope LM, Schmieder RE, Sirnes PA, Sleight P, Viigimaa M, Waeber B, Zannad F, Redon J, Dominiczak A, Narkiewicz K, Nilsson PM, Burnier M, Viigimaa M, Ambrosioni E, Caufield M, Coca A, Olsen MH, Schmieder $\mathrm{RE}$, Tsioufis $\mathrm{C}$, van de Borne $\mathrm{P}$, Zamorano JL, Achenbach S, Baumgartner H, Bax JJ, Bueno H, Dean V, Deaton C, Erol C, Fagard R, Ferrari R, Hasdai D, Hoes AW, Kirchhof P, Knuuti J, Kolh P, Lancellotti P, Linhart A, Nihoyannopoulos P, Piepoli MF, Ponikowski P, Sirnes PA, Tamargo JL, Tendera M, Torbicki A, Wijns W, Windecker S, Clement DL, Coca A, Gillebert TC, Tendera M, Rosei EA, Ambrosioni E, Anker SD, Bauersachs J, Hitij JB, Caulfield M, De Buyzere M, De Geest S, Derumeaux GA, Erdine S, Farsang C, Funck-Brentano C, Gerc V, Germano G, Gielen S, Haller H, Hoes AW, Jordan J, Kahan T, Komajda M, Lovic D, Mahrholdt H, Olsen MH, Ostergren J, Parati G, Perk J, Polonia J, Popescu BA, Reiner Z, Rydén L, Sirenko Y, Stanton A, Struijker-Boudier H, Tsioufis C, van de Borne P, Vlachopoulos C, Volpe M, Wood DA. 2013 ESH/ESC guidelines for the management of arterial hypertension: the Task Force for the Management of Arterial Hypertension of the European Society of Hypertension (ESH) and of the European Society of Cardiology (ESC). Eur Heart J. 2013;34:2159-219.

15. Omboni S, Sala E. The pharmacist and the management of arterial hypertension: the role of blood pressure monitoring and telemonitoring. Expert Rev Cardiovasc Ther. 2015;13:209-21.

16. Omboni S, Guarda A. Impact of home blood pressure telemonitoring and blood pressure control: a meta-analysis of randomized controlled studies. Am J Hypertens. 2011;24:989-98.

17. McManus RJ, Mant J, Haque MS, Bray EP, Bryan S, Greenfield SM, Jones MI, Jowett S, Little P, Penaloza C, Schwartz C, 
Shackleford H, Shovelton C, Varghese J, Williams B, Hobbs FD, Gooding T, Morrey I, Fisher C, Buckley D. Effect of selfmonitoring and medication self-titration on systolic blood pressure in hypertensive patients at high risk of cardiovascular disease: the TASMIN-SR randomized clinicaltrial. JAMA. 2014;312:799-808.

18. Stergiou GS, Bliziotis IA. Home blood pressure monitoring in the diagnosis and treatment of hypertension: a systematic review. Am J Hypertens. 2011;24:123-134.

19. Association For The Advancement Of Medical Instrumentation. American National Standard for Electronic or Automated Sphygmomanometers: ANSI/AAMI SP10-1993. Arlington, Virginia: AAMI; 1993.

20. O'Brien E, Petrie J, Littler WA, de Swiet M, Padfield PL, Altman D, Bland M, Coats A, Atkins N The British Hypertension Society Protocol for the evaluation of blood pressure measuring devices. J Hypertens. 1993;11: S43-63.

21. O'Brien E, Pickering T, Asmar R, Myers M, Parati G, Staessen J, Mengden T, Imai Y, Waeber B, Palatini P, Gerin W. Working Group on Blood Pressure Monitoring of the European Society of Hypertension International Protocol for validation of blood pressure measuring devices in adults. Blood Press Monit. 2002;7:3-17.

22. O'Brien E, Atkins N, Stergiou G, Karpettas N, Parati G, Asmar R, Imai Y, Wang J, Mengden T, Shennan A.Working Group on Blood Pressure Monitoring of the European Society of Hypertension European Society of Hypertension International Protocol revision 2010 for the validation of blood pressure measuring devices in adults. Blood Press Monit. 2010;15:23-38.

23. Akpolat T, Erdem Y, Derici U, Erturk S, Caglar S, Hasanoglu E, Karatan O, Sindel S, Turgan C. Use of homesphygmomanometers in Turkey: a nation-wide survey. Hypertens Res. 2012;35:356-61.

24. Altun B, Arici M, Nergizoğlu G, Derici U, Karatan O, Turgan C, Sindel S, Erbay B, Hasanoğlu E, Cağlar S.for the Turkish Society of Hypertension and Renal Diseases Prevalence, awareness, treatment and control of hypertension in Turkey (the PatenT study) in 2003. J Hypertens. 2005;23:1817-1823.

25. Arici M, Turgan C, Altun B, Sindel S, Erbay B, Derici U, Karatan O, Erdem Y, Hasanoglu E, Caglar S.Turkish Society of Hypertension and Renal Diseases Hypertension incidence in Turkey (HinT): a population-based study. J Hypertens. 2010;28:240-244.

26. Erdem Y, Arici M, Altun B, Turgan C, Sindel S, Erbay B, Derici U, Karatan O, Hasanoglu E, Caglar S. The relationship between hypertension and salt intake in Turkish population: SALTURK study. Blood Press. 2010;19:313-318.

27. Sengul S, Akpolat T, Erdem Y, Derici U, Arici M, Sindel S, Karatan O, Turgan C, Hasanoglu E, Caglar S, Erturk S.Turkish Society of Hypertension and Renal Diseases Changes in hypertension prevalence, awareness, treatment, and control rates in Turkey from 2003 to 2012. J Hypertens. 2016;34:1208-17.

28. Mancia G, De Backer G, Dominiczak A, Cifkova R, Fagard R, Germano G, Grassi G, Heagerty AM, Kjeldsen SE, Laurent S, Narkiewicz K, Ruilope L, Rynkiewicz A, Schmieder RE, Boudier HA, Zanchetti A, Vahanian A, Camm J, De Caterina R, Dean V, Dickstein K, Filippatos G, Funck-Brentano C, Hellemans I, Kristensen SD, McGregor K, Sechtem U, Silber S, Tendera M, Widimsky P, Zamorano JL, Erdine S, Kiowski W, Agabiti-Rosei E, Ambrosioni E, Lindholm LH, Viigimaa M, Adamopoulos S, Agabiti-Rosei E, Ambrosioni E, Bertomeu V, Clement D, Erdine S, Farsang C, Gaita D, Lip G, Mallion JM, Manolis AJ, Nilsson PM, O’Brien E, Ponikowski P, Redon J, Ruschitzka F, Tamargo J, vanZwieten $\mathrm{P}$, Waeber B, Williams B.Management of Arterial Hypertension of the European Society of Hypertension; European Society of Cardiology. 2007 Guidelines for the Management of Arterial Hypertension: The Task Force for the Management of
Arterial Hypertension of the European Society of Hypertension (ESH) and of the European Society of Cardiology (ESC). J Hypertens. 2007;25:1105-1187.

29. dabl ${ }^{\circledR}$ Educational Trust. Available from: http://www.dableducational.org.

30. BHS-Blood Pressure List. Available from: http://www.bhsoc.org/ blood_pressure_list.stm.

31. Cuspidi C, Meani S, Fusi V, Salerno M, Valerio C, Severgnini B, Catini E, Leonetti G, Magrini F, Zanchetti A. Home blood pressure measurement and its relationship with blood pressure control in a large selected hypertensive population. J Hum Hypertens. 2004;18:725-31.

32. Obara T, Ohkubo T, Asayama K, Metoki H, Inoue R, Kikuya M, Kato T, Tanaka K, Hara A, Hashimoto J, Totsune K, Imai Y, JHOME Study Group. Home blood pressure measurements associated with better blood pressure control: the J-HOME study. J Hum Hypertens. 2008;22:197-204.

33. Bray EP, Holder R, Mant J, McManus RJ. Does self-monitoring reduce blood pressure? Meta-analysis with meta-regression of randomized controlled trials. Ann Med. 2010;42:371-86.

34. Penaloza-Ramos MC, Jowett S, Mant J, Schwartz C, Bray EP, Sayeed Haque M, Richard Hobbs FD, Little P, Bryan S, Williams B, McManus RJ. . Cost-effectiveness of self-management of blood pressure in hypertensive patients over 70 years with suboptimal control and established cardiovascular disease or additional cardiovascular risk diseases (TASMIN-SR). Eur J Prev Cardiol. 2016;23:902-12.

35. Levy J, Gerber LM, Wu X, Mann SJ. Nonadherence to recommended guidelines for blood pressure measurement. J Clin Hypertens (Greenwich). 2016;18:1157-1161.

36. Saito I, Kario K, Kushiro T, Teramukai S, Yaginuma M, Mori Y, Okuda Y, Shimada K. Home blood pressure and cardiovascular risk in treated hypertensive patients: the prognostic value of the first and second measurements and the difference between them in the HONEST study. Hypertens Res. 2016;39:857-862.

37. Ayala C, Tong X, Neeley E, Lane R, Robb K, Loustalot F. Home blood pressure monitoring among adults-American Heart Association Cardiovascular Health Consumer Survey 2012. J Clin Hypertens (Greenwich). 2017;19:584-591.

38. Ostchega Y, Zhang G, Kit BK, Nwankwo T. Factors associated with home blood pressure monitoring among US adults: National Health and Nutrition Examination Survey, 2011-2014. Am J Hypertens. 2017;30:1126-1132.

39. Bibbins-Domingo K, Chertow GM, Coxson PG, Moran A, Lightwood JM, Pletcher MJ, Goldman L. Projected effect of dietary salt reductions on future cardiovascular disease. N Engl J Med. 2010;362:590-9.

40. Ndip Agbor V, Temgoua MN, Noubiap JJ. Scaling up the use of home blood pressure monitoring in the management of hypertension in low-income countries: a step towards curbing the burden of hypertension. $\mathrm{J}$ Clin Hypertens (Greenwich). 2017;19:786-789.

41. Akpolat T, Aydogdu T, Erdem E, Karatas A. Inaccuracy of homesphygmomanometers: a perspective from clinical practice. Blood Press Monit. 2011;16:168-71.

42. Jung MH, Kim GH, Kim JH, Moon KW, Yoo KD, Rho TH, Kim CM. Reliability of home blood pressure monitoring: in the context of validation and accuracy. Blood Press Monit. 2015;20:215-20.

43. O'Brien E. Ambulatory blood pressure measurement: the case for implementation in primary care. Hypertension. 2008;51:1435-41.

44. Graves JW, Bailey KR, Sheps SG. The changing distribution of arm circumferences in NHANES III and NHANES 2000 and its impact on the utility of the 'standard adult' blood pressure cuff. Blood Press Monit. 2003;8:223-227. 